\title{
Autista no mercado de trabalho: uma comparação e mensuração da capacidade de produção de pessoas autistas versus neurotípica
}

\author{
Autistic in the labor market: a comparison and measurement of the production capacity of autistic \\ versus neurotypical people
}

Autista en el mercado laboral: una comparación y medición de la capacidad de producción de las personas autistas frente a las neurotípicas

Recebido: 04/05/2021 | Revisado:10/05/2021 | Aceito: 12/05/2021 | Publicado: 29/05/2021

\author{
Rose Kelly Irene Santos da Conceição Melicio \\ ORCID: https://orcid.org/0000-0003-1683-4678 \\ Universidade Paulista, Brasil \\ E-mail: rkm.sud@gmail.com \\ Oduvaldo Vendrametto \\ ORCID: https://orcid.org/0000-0003-2430-6138 \\ Universidade Paulista, Brasil \\ E-mail: oduvaldov@gmail.com \\ Pedro Luiz Oliveira Costa Neto \\ ORCID: https://orcid.org/0000-0002-6987-2996 \\ Universidade Paulista, Brasil \\ E-mail: pedroluiz@plocn.com
}

\begin{abstract}
Resumo
Em 2012, com a Lei Berenice Piana se iniciaram as discussões sobre as conquistas das pessoas com Transtorno Espectro Autista (TEA), que têm conquistado seu espaço no mercado de trabalho, porém o estigma de incapacidade acaba dificultando essa evolução. Para contribuir e disseminar os fatores que afetam a efetiva inclusão social dos autistas no mercado de trabalho, pesquisas têm se apresentado dessa direção. O intuito do presente estudo é mensurar e comparar a capacidade produtiva profissional das pessoas com TEA versus uma pessoa Neurotípica (pessoa considerada normal ou sem características autistas), tomando como caso empresas contratantes dessa mão de obra. Para esse objetivo foi realizado uma abordagem exploratória e quantitativa de natureza básica. A constatação foi que as restrições impostas pela ignorância da capacidade autista inibem a utilização máxima ou ideal das habilidades de pessoas com TEA. Entretanto, quando orientadas e as funções nas quais suas habilidades/competências possam ser reveladas, têm um índice igual ou maior de produtividade quando comparadas com pessoas neurotípicas.
\end{abstract}

Palavras-chave: Capacidade produtiva; Autismo; Pessoas com transtorno espectro autista (TEA); Inclusão no mercado de trabalho.

\begin{abstract}
In 2012, with the Berenice Piana Law, discussions began about the achievements of people with Autism Spectrum Disorder (ASD), who have conquered their space in the labor market, but the stigma of disability ends up hindering this evolution. To contribute to and disseminate the factors that affect the effective social inclusion of autistic people in the labor market, research has been presented in this direction. The aim of this study is to measure and compare the professional productive capacity of people with ASD versus a Neurotypical person (person considered normal or without autistic characteristics), taking as a case contracting companies of this workforce. For this purpose, an exploratory and quantitative approach of a basic nature was carried out. The finding was that the restrictions imposed by ignorance of autistic ability insure the maximum or ideal use of the abilities of people with ASD. However, when oriented and in the functions in which their skills/competencies can be revealed, they have an equal or higher productivity index when compared to neurotypical people.
\end{abstract}

Keywords: Productive capacity; Autism; People with autism spectrum disorder (ASD); Inclusion in the labor Market.

\section{Resumen}

En 2012, con la Ley Berenice Piana, comenzaron las discusiones sobre los logros de las personas con Trastorno del Espectro Autista (TEA), que han conquistado su espacio en el mercado laboral, pero el estigma de la discapacidad termina obstaculizando esta evolución. Para contribuir y difundir los factores que afectan a la inclusión social efectiva de las personas autistas en el mercado laboral, se ha presentado una investigación en esta dirección. El objetivo de este estudio es medir y comparar la capacidad productiva profesional de las personas con TEA frente a una persona neurotípica (persona considerada normal o sin características autistas), tomando como caso la contratación de 
empresas de esta plantilla. A tal fin, se llevó a cabo un enfoque exploratorio y cuantitativo de carácter básico. El hallazgo fue que las restricciones impuestas por el desconocimiento de la capacidad autista aseguran el uso máximo o ideal de las habilidades de las personas con TEA. Sin embargo, cuando están orientados y en las funciones en las que se pueden revelar sus habilidades /competencias, tienen un índice de productividad igual o superior en comparación con las personas neurotípicas.

Palabras clave: Capacidad productiva; Autismo; Personas con trastorno del espectro Autista (TEA); Inclusión en el mercado laboral.

\section{Introdução}

O termo "Autismo" foi usado pela primeira vez por Plouller em 1906, referindo-se aos pacientes que faziam relação a tudo no mundo e à sua volta, consigo mesmo, ou seja, isolamento frequente, em alguns casos considerado processo psicótico (Ribeiro, 2015). O autismo tem sido definido nos últimos anos por pesquisadores, médicos, psicólogos, dentre outros como Transtorno do Espectro Autista (TEA), sendo um transtorno mental, ou seja, não é um distúrbio psicológico ou psiquiátrico, e sim, um distúrbio no neurodesenvolvimento que afeta a função cerebral e percepções sensoriais, ocasionando déficits na comunicação, interação social e comportamental, distribuídos em diversos níveis manifestações e além destes pode manifestar padrões restritivos e repetitivos de comportamento (Klin, 2006 ${ }^{\mathrm{a}}$; Cardoso et al., 2021) .

A lei de cotas com o objetivo de incluir pessoas com deficiência foi uma maneira de superar os obstáculos dentro das organizações. Entretanto, não tem sido o suficiente devido as discrepâncias vivenciadas, pois, os empregam para atender os protocolos legais, contudo, com funções restritas, sem muita importância ou inferior de suas qualificações profissionais, mesmo que possua habilidades para exercê-la com competência.

No Brasil, mesmo havendo cerca de 3 milhões de pessoas com algum tipo de deficiência com ensino superior, somente 30\% de vagas são ofertadas a esse público (Instituto Ethos e da Rede Empresarial de Inclusão, 2019).

Diante desse cenário, como o portador de Transtorno Espectro Autista pode subsistir de forma digna se não lhe é dada oportunidade de condições de trabalho? Entretanto, mesmo com a garantia da lei 12.764/12 ao qual as pessoas dentro do espectro obtiveram o reconhecimento como deficientes, são afetados os seus respectivos direitos pelo preconceito de inábil (Brasil, 2012).

O intuito deste trabalho consiste em pesquisar esse estigma, ou seja, comparar a capacidade produtiva de um colaborador com TEA versus um neurotípico (pessoas que não apresentam divergências no desenvolvimento neurológico, portanto sem autismo (Attwood, 1998) ou ditas como normais), nas empresas contratantes de autistas. A hipótese assumida é que existe a plena equipolência das pessoas dentro do espectro autista com as demais pessoas no que se refere à eficiência e competência no trabalho.

Este artigo está organizado em seções, sendo a primeira uma breve introdução ao tema, a segunda uma revisão de literatura e a terceira, pesquisa com a comparação e mensuração da capacidade produtiva, seguida pelas conclusões. Por fim, são apresentadas as referências bibliográficas utilizadas na pesquisa.

\section{Referencial Teórico}

Com a origem desconhecida, assim como sua cura o Transtorno Espectro Autista, têm chamado a atenção de muitas pesquisas. Entretanto, o conhecimento sobre o autismo, até hoje são incertos, por isso, os tratamentos são para amenizar seus efeitos, que podem se manifestar de maneira leve (possibilitando uma vida normal ou quase normal) ou outros graus mais comprometedores.

No Brasil, com a lei de cotas, admite-se que as pessoas com deficiência, como no caso as com TEA, porém, por falta de informações adequadas, por ter alguma restrição ou limitação em uma área, recebam um estereótipo de pessoa inábil como 
um todo. Sendo assim, sua capacidade produtiva ser questionada e pressionada quanto ao saber fazer e ao ser capaz. (Lobato, 2009).

No âmbito internacional, desde 1988 estudos mostram que as pessoas com Transtorno Espectro Autista podem ter um emprego remunerado, mas na prática, ainda em 2019 poucos conseguiram esse êxito (Ritvo et al., 1988; Scott et al., 2019). Quando o conseguem geralmente os cargos ofertados são de baixa qualificação, mesmo aos que tenham capacidade para realização (Jansen; Rombout, 2013). Ainda há vários obstáculos a serem sobrepujados pelas pessoas autistas mesmo possuindo habilidades e desejos de trabalharem (Hendricks, 2010). Entretanto, isso pode ser o reflexo da má comunicação entre empregadores e trabalhadores autistas. No modo geral ocasionada das dificuldades encontradas pelas pessoas com TEA para entender as relações sociais e gerenciar sua hipersensibilidade sensorial, se tornando assim, vítimas de organizações inadequadas e sem preparo. (Klin, 2006).

\section{Metodologia}

Com o intuito de observar o cenário dentro das empresas sobre a capacidade de produção autista, optou-se por revisão de bibliográfica e uma pesquisa descritiva com avaliações qualitativas e quantitativas, entretanto restrita a uma amostragem limitada devido a pouca disponibilidade de acesso. Os dados foram coletados em três empresas com diferentes portes e ramos no ano de 2019, na cidade de São Paulo.

A pesquisa descritiva é estabelecida por Richardson (2015) como: os estudos de natureza propõem-se a investigar o "que é", isto é, descobrir as características de um fenômeno como tal. São considerados como objetos de estudo uma situação específica, um grupo ou um indivíduo. Três casos específicos de empresas, no Brasil foram objeto desta pesquisa.

O procedimento deu-se na primeira empresa por observância empírica em um dia de trabalho de um colaborador dentro do espectro no seu ambiente de trabalho, analisando seu comportamento com clientes e colegas de trabalho.

$\mathrm{Na}$ segunda empresa, isso ocorreu em duas etapas. Primeira: coleta de dados, que foram extraídos por meio de entrevista (com perguntas abertas) realizada pessoalmente com a Líder de Gerenciamento de Dados Corporativos no ano de 2019. Segunda etapa: após aferimento das informações da entrevista, como: os dados dos comportamentos gerais (como o levantamento do tempo com as paradas para beber água, ir ao banheiro, celular, internet e networking) e o indicador da meta mínima estabelecida, comparou-se a produção entre funcionários autistas versus funcionários neurotípicos, por meio do cálculo de capacidade instalada, disponível, efetiva e realizada.

$\mathrm{Na}$ terceira empresa, a primeira fase consiste em entrevistas (com perguntas abertas e declarações das experiências dos envolvidos) à Diretora Geral, ao Supervisor da Equipe e ao Colaborador ligado ao Transtorno Espectro Autista (TEA). A mensuração dos resultados, se deu por meio dos dados tabulados de forma quantitativa e continua pelo supervisor da equipe. Considerando os primeiros 90 dias de trabalho de ambos os funcionários (autista e neurotípico) na mesma função, nas mesmas condições físicas, estruturais e ambientes de trabalho.

O mesmo questionário, foi aplicado nas empresas dois e três, conforme abaixo:

1) O que os motivou a contratarem mão de obra de pessoas com Transtorno Espectro Autista? A primeira questão foi direcionada sobre a motivação da empresa para a contratação de pessoas com TEA.

2) Quais as principais funções/atribuições realizadas pelo colaborador TEA?

3) Existe alguma função/atribuição que não conseguiu desempenhar ou desempenha com maior êxito devido ao fato de estar dentro do Espectro?

A segunda e a terceira perguntas tiveram o intuito de levantar informações sobre as atribuições e desempenho desses funcionários.

4) Quais os desafios que a empresa e os colegas de trabalho encontraram para sua inclusão? 


\section{5) Quais as dificuldades encontradas pelo com TEA?}

As questões quatro e cinco foram direcionadas aos desafios e dificuldades de inclusão entre o colaborador dentro do espectro autista e os outros colaboradores.

6) Quais os pontos positivos ao contratarem uma pessoa Autista?

A sexta questão objetivou o levantamento de dados sobre as vantagens encontradas pela contratação de pessoas com TEA.

7) Existe plano de carreira para o funcionário com TEA? Se sim quais as possibilidades?

O sétimo questionamento se referiu ao plano de carreira e foi respondido que qualquer colaborador, inclusive para esses com autismo.

\section{8) Como é avaliado o nível de produção desse colaborador com TEA?}

9) Como definem a sua capacidade produtiva?

A oitava e nona questões estão relacionadas ao método de mensuração do nível de produção.

10) Acredita que qualquer tipo de empresa e porte pode contratar um autista?

A décima foi atribuída sobre a opinião referente a que porte de empresa estaria pronta para esse tipo de contratação.

11) Qual é a média de custo adicional na contratação de pessoas autistas?

12) A empresa tem projeto para mais contratações de pessoas com TEA?

13) Existem relatórios que possam ser compartilhados para comparação de um funcionário neurotípico (normal) e um autista?

As demais questões foram focadas nos custos, intenções de futuras contratações e a existência de relatórios de produção.

\section{Resultados e Discussão}

Neste item é apresentado os resultados e a discussão das investigações pesquisadas em três empresas que estão no Brasil. Visando chegar aos objetivos do presente trabalho.

\subsection{Loja de produtos de informática - Empresa $X$}

A empresa possui uma rede de lojas distribuídas pelo Estado de São Paulo, tendo como modelo de negócio franquias. Foi acompanhado, durante um dia, a rotina de um rapaz de dezoito anos diagnosticado com TEA. Ele é acompanhado pela Associação de Pais, Amigos e Educadores de Autista - APAEA, em uma das cidades do Estado de São Paulo, e uma terapeuta particular que lhe dá suporte em situações cotidianas.

Sua função consistia em atender os clientes, dar suporte aos colegas de trabalho com a localização de material em estoque e informações de características e suporte técnico dos produtos e estava aproximadamente há um ano na empresa, porém só foi registrado como balconista recentemente. Esse funcionário com TEA ainda oscila em seu comportamento ao atender diretamente o cliente, ocorrendo algumas crises de ansiedade ao ser confrontado por parte dos clientes insatisfeitos com algum produto comprado. No entanto, seus colegas afirmam ser ele de grande valia para esclarecer dúvidas minuciosas sobre as características e diferenças dos produtos, melhor do que qualquer outro com sua habilidade de gravar informações de todos os produtos, além de saber onde encontrar rapidamente cada item do estoque sem precisar consultar o sistema.

Esse funcionário com TEA relata que atender os clientes ainda é, por ser tudo muito novo, um desafio a cada momento e dia, sendo sua preferência por área administrativa e tem fascinação pelas características técnicas dos produtos e do estoque, por lhe trazer uma rotina constante. 
O comportamento das pessoas dentro de uma organização é complexo, dependendo do ambiente. Segundo Slack et al. (2009, p. 249), dentro da Engenharia de Produção no âmbito de Ergonomia, existe uma relação direta entre o ambiente de trabalho e a capacidade de produzir. Voltando à análise da situação mencionada, não é o suficiente só ofertar uma vaga sem proporcionar um ambiente adequado ou colocar o autista em função no qual não possa desenvolver suas habilidades. Como fica evidenciado no case, sua memorização pode ser mais bem aproveitada.

\subsection{Multinacional da área química no Brasil}

Essa empresa consiste em uma indústria com polos em várias partes do mundo, inclusive no Brasil, cujo produto é fonte de matéria-prima para derivados diversos.

O levantamento dos dados dessa investigação se originou com a entrevista realizada pessoalmente com a Líder de Gerenciamento de Dados Corporativos no ano de 2019. Uma das atribuições da entrevistada é gerenciar a equipe do setor de cadastramento de fornecedores e clientes da empresa no mundo. O setor emprega vinte e três funcionários, entre esses, por meio de serviços terceirizados, duas funcionárias deficientes auditivas e dois com Transtorno Espectro Autista. Ambos os casos não fazem parte de contratação por cota.

Baseado nas informações prestadas na entrevista, conclui-se que foram necessárias algumas adaptações em ambos os lados (dos colaboradores autistas inserido, como dos demais funcionários) mas, sem grandes ocorrências. Com os dados fornecidos como: o tempo da jornada de trabalho, comportamentos gerais (com as médias das paradas para beber água, ir ao banheiro, celular, internet e Networking) foram utilizados para o cálculo da capacidade instalada, disponível x efetiva e realizada produzidos pelos funcionários autistas versus dos demais funcionários neurotípicos. O resultado visualiza-se no Tabela 1:

Tabela 1 - Comparação da Capacidade Produtiva do Colaborador com TEA x Colaborador Nerotípico.

\begin{tabular}{|c|c|}
\hline Colaborador com TEA & Colaborador Nerotípico \\
\hline \multicolumn{2}{|l|}{$\begin{array}{l}\text { Capacidade Instalada }=30 \text { dias (comerciais) x } 24 \text { horas x } 2,5^{*} \\
\text { CI }=\mathbf{1 . 8 0 0} / \text { Mês ambos }\end{array}$} \\
\hline \multicolumn{2}{|c|}{$\begin{array}{l}\text { Capacidade Disponível }=20 \text { dias (Segunda a Sexta) x } 8 \text { horas (horário Administrativo x } 2,5 *= \\
\text { CD }=400 / \text { Mês ambos }\end{array}$} \\
\hline \multicolumn{2}{|c|}{$\begin{array}{l}\text { Capacidade Efetiva }=20 \text { dias }(\text { Segunda a Sexta) } \times 8 \text { horas }(\text { horário Administrativo }= \\
\text { 160/mês }-4 \text { horas de parada prevista }(\text { Horas em reuniões e confraternizações por mês })=156 / \text { mês } \times 2,5^{*}= \\
\text { CE }=390 / \text { Mês ambos }\end{array}$} \\
\hline $\begin{array}{l}\text { Capacidade Realizada }=20 \text { dias (Segunda a Sexta) x } 8 \text { horas } \\
\text { (horário Administrativo }=160 / \text { mês } \\
-4 \text { horas de parada prevista (Horas em reuniões e } \\
\text { confraternizações por mês) }=156 / \text { mês } \\
-5^{* *} \text { horas de paradas imprevistas }(+ \text { ou }-15 \text { min. Diários em } \\
\text { beber água, ir ao banheiro, celular, internet e Networking) }= \\
\mathbf{1 5 1 / m e ̂ s ~} 2,5^{*}= \\
\mathbf{C R}=\mathbf{3 7 7 , 5} \text { ou } \mathbf{3 7 8} / \text { Mês }\end{array}$ & $\begin{array}{l}\text { Capacidade Realizada }=20 \text { dias }(\text { Segunda a Sexta) x } 8 \text { horas } \\
\text { (horário Administrativo }=160 / \text { mês } \\
-4 \text { horas de parada prevista (Horas em reuniões e confraternizações } \\
\text { por mês }=156 / \text { mês } \\
-10 * * * \text { horas de parada imprevista }(+ \text { ou }-30 \text { min. Diários em } \\
\text { beber água, ir ao banheiro, celular, internet e Networking) }=\mathbf{1 4 6} / \mathbf{m e ̂ s} \\
\text { x } 2.5^{*}= \\
\text { CR }=\mathbf{3 6 5} \text { / Mês }\end{array}$ \\
\hline \multicolumn{2}{|c|}{ Grau de utilização $=390($ Efetiva $) \div 400($ Disponível $)=\mathbf{G U}=\mathbf{0 , 9 8}$ ou $98 \%$ ambos } \\
\hline \multicolumn{2}{|c|}{ Grau disponível $=400$ (Disponível $) \div 1800$ (Instalada $)=\mathbf{G D}=\mathbf{0 , 2 2}$ ou $22 \%$ ambos } \\
\hline $\begin{array}{l}\text { Índice Efetivo }=378(\text { Realizada }) \div 390(\text { Efetiva })= \\
\text { GR }=0,97 \text { ou } 97 \%\end{array}$ & $\begin{array}{l}\text { Índice Efetivo }=365(\text { Realizada }) \div 390(\text { Efetiva })= \\
\text { GR }=0,94 \text { ou } 94 \%\end{array}$ \\
\hline \multicolumn{2}{|c|}{ * (20 é a meta mínima de produção diária p/ $8 \mathrm{~h}$ de trabalho, logo: $20 \div 8=2,5$ é a média de produção por hora) } \\
\hline (+ ou -15 min. diários x 20 dias $=300$ min. no mês, logo: 300 & $0=5$ horas) \\
\hline
\end{tabular}

Fonte: Autores (2019). 
Segundo Peinado; Graemi, (2007) entende-se como capacidade diferentes categorias como:

- Capacidade Instalada - tem como definição a capacidade máxima de uma unidade produtiva trabalhando ininterruptamente e não considerando perdas;

- Capacidade Disponível - quando se considera a quantidade máxima que um processo pode produzir durante a jornada de trabalho disponível. Também não considera as perdas;

- Capacidade Efetiva - aludi a capacidade disponível subtraindo as perdas planejadas (paradas de setup, manutenção preventiva etc.);

- Capacidade Realizada - se refere quando a capacidade obtida subtraindo as perdas planejadas e não planejadas.

Conforme Slack et al. (2009, p. 4 ), “capacidade de uma operação é o máximo nível de atividade em um determinado período de tempo que o processo pode realizar sob condições normais de operação."

Para Staudt; Coelho; Gonçalves, (2011) atribuem a capacidade produtiva quando as decisões gerenciais, assim como o desempenho econômico da empresa são afetados pela mensuração e o relato da mesma.

Ademais, Moreira (2017) defende que a capacidade é a competência ou condições de atingir determinadas quantidades ou níveis, é uma representação de forma quantitativa limite versus uma demanda.

Portanto, conclui-se que os colaboradores com TEA é mais concentrado, não dispersam com atendimento de celular e internet, segundo a Líder de Gerenciamento de Dados Corporativos, tendo uma produção maior que a média, no mínimo de 3\% (três porcento) que representam no fim de um ano (240 dias úteis anuais , ou 20 dias mensais x 12 meses) x 20 meta mínima diária $=4800$ × 3\% = 144 atendimentos) e a análise pessoal da Líder de Gerenciamento é que essa superioridade apresentada também de forma qualitativa devido ao seu foco.

\subsection{Empresa do Setor de Tecnologia}

Entretanto, outra empresa investigada iniciou suas atividades em 2002 e lidera o mercado nacional desde 2004. Suas atividades centralizam-se no uso de tecnologias e inteligência artificial, como sensores infravermelhos, e outros usados na indústria 4.0 para contagem de fluxo de pessoas, fornecendo levantamento de informações aos seus clientes nacionais (como shoppings; empresas de telefonia etc.) e internacionais (como Adidas e The North Face) para marketing e gestão. A empresa possui 25 (vinte e cinco) colaboradores, sendo um deles com Transtorno Espectro Autista. Em visita à empresa sediada em Barueri/ SP, a entrevista foi com a Diretora Geral da empresa, o Supervisor da equipe e o colaborador com do Transtorno Espectro Autista (TEA).

De acordo com as informações extraídas na entrevista, identificou-se que inicialmente foi necessário desmistificar como seria trabalhar com autista. E sempre é bom lembrar que ele (no caso do seu colaborador) é literal, ou seja, não entende expressões com duplo sentido. E as adaptações que foram necessários se restringiu ao local em que o colaborador autista se sentava, por ser próximo ao corredor, o incomodava com o fluxo de pessoas passando, foi então colocado no canto da parede solucionando o problema. Conforme o layout Ilustração 1 abaixo: 
Ilustração 1 - Layout do Ambiente de Trabalho do Colaborador com TEA.
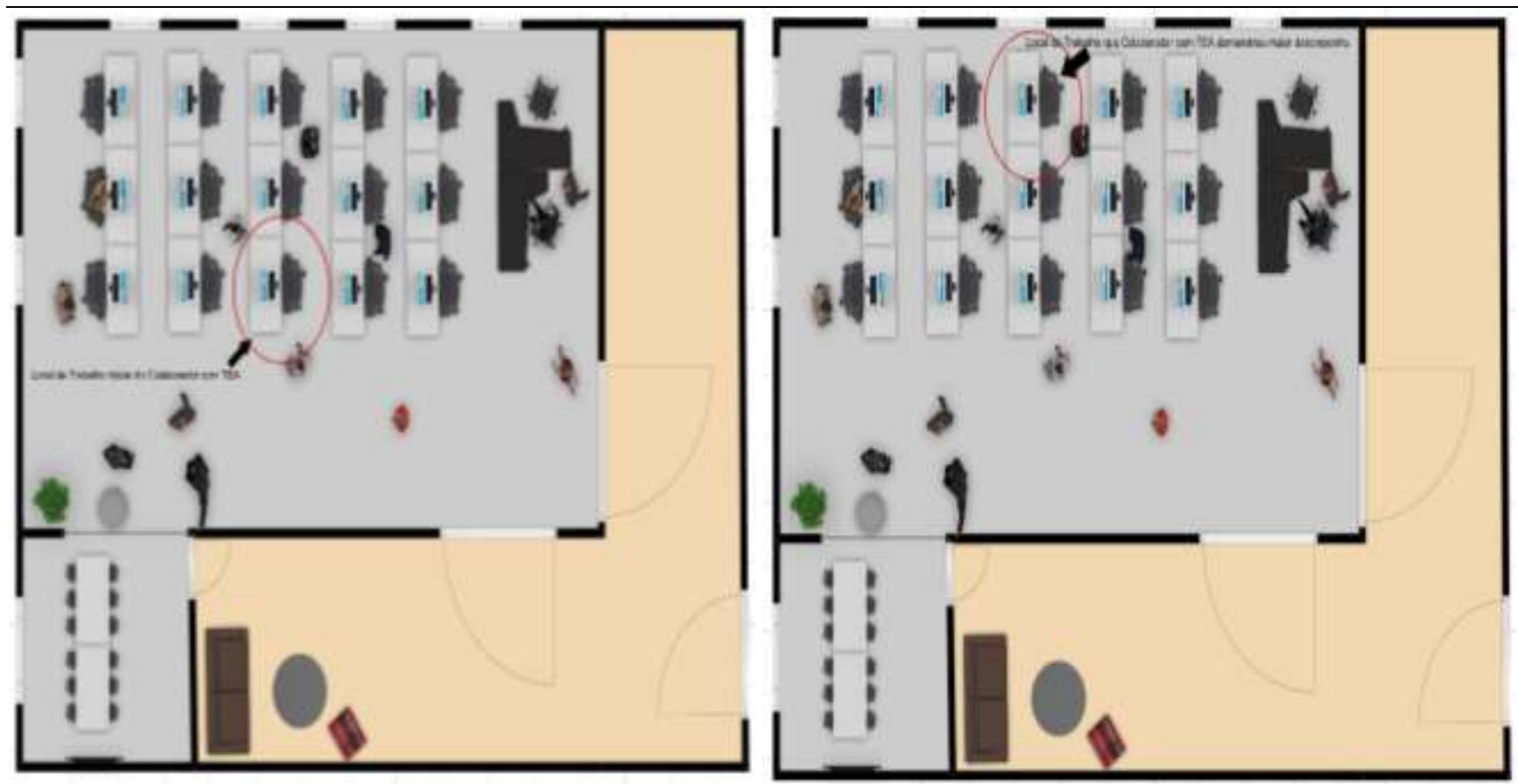

Fonte: Autores (2019).

Como análise da situação exposta, existem as práticas das vertentes da Ergonomia, que são sustentadas por dois pilares, um de gerar conhecimento sobre as condições de trabalho e o outro, a ação de transformação das condições de trabalho, tendo como perspectiva melhorar a relação homem/trabalho. Como ocorreu observado no layout na ilustração 1, uma simples mudança de lugar resultou em melhor produtividade.

O sistema de produção da referida empresa é identificado por “chamado" (metragem de vídeos), e não se consegue a informação de quantas horas de vídeo (objeto de análise pelo colaborador) tem em cada "chamado" aberto.

Os números levantados consideraram os primeiros 90 dias de trabalho do portador de TEA versus os primeiros 90 dias da última funcionária que exerceu a mesma função. Tiveram o mesmo período de contratação, nas mesmas condições físicas e ambiente de trabalho. Foram tabulados os dados de forma quantitativa e contínua pelo supervisor da equipe, conforme no Tabela 2.

Tabela 2 - Capacidade Produtiva do Colaborador com TEA x Colaborador Neurotípico.

\begin{tabular}{|c|c|c|c|c|c|c|}
\hline & $\begin{array}{l}\text { Produção } \\
\text { Dia } 1\end{array}$ & $\begin{array}{l}\text { Produção } \\
\text { Dia } 2\end{array}$ & $\begin{array}{l}\text { Produção } \\
\text { Dia } 3\end{array}$ & $\begin{array}{l}\text { Produção } \\
\text { Dia ...... }\end{array}$ & $\begin{array}{l}\text { Produção } \\
\text { Dia } 89\end{array}$ & $\begin{array}{l}\text { Chamados Atendidos no final } \\
\text { dos primeiros } 90 \text { dias } \\
\text { trabalho de } \\
\text { funcionários. }\end{array}$ \\
\hline $\begin{array}{l}\text { Funcionário } \\
\text { Autista }\end{array}$ & $\bar{x}$ & $\bar{x}$ & $\bar{x}$ & $\bar{x}$ & $\mathrm{x}$ & $\mathrm{n} 1+\mathrm{n} 2+\mathrm{n} 3+\mathrm{n} . . .+\mathrm{n} 90=144$ \\
\hline $\begin{array}{l}\text { Funcionário } \\
\text { Neurotípico }\end{array}$ & $\mathrm{x}$ & $\mathrm{x}$ & $\mathrm{x}$ & $\mathrm{x}$ & $\mathrm{x}$ & $n 1+n 2+n 3+n \ldots .+n 90=111$ \\
\hline
\end{tabular}


A análise realizada sobre a diferença de produção entre o funcionário Autista e o Neurotípico se obteve:

$$
\begin{gathered}
\text { PA }(144)-\text { PN }(111)=33 \text { chamados. } \\
\text { PA }(144) \div \text { PN }(111)=1,2973 \text { ou } 29,73 \%
\end{gathered}
$$

Se consideramos que:

PA = Produção Autista;

PN = Produção Neurotípico

Logo, a produção do funcionário dentro do espectro foi cerca de 30\% superior à funcionária neurotípica.

A Mensuração consiste no processo de quantificar a ação, tornando objetiva a subjetividade do desempenho, sendo descritos os dados em números para compreender os fatos e fenômenos de interesse (Slack et al., 2009; Silva Júnior \& Costa, 2014).

Foi realizada entrevista aberta com o supervisor da equipe. Foi questionado sobre como é trabalhar com um funcionário autista. O supervisor direto do funcionário com TEA e de mais quatro colaboradores respondeu que a melhor forma está em como solicitar as coisas. Sendo de formas diretas e claras, o resultado será a entrega do que foi solicitado sempre com êxito, qualidade, honestidade e precisão; atributos que valorizam as habilidades do autistas e passam maior confiança do serviço prestado por ele.

Quando questionado sobre um aspecto que esse colaborador com TEA teria a ser desenvolvido, relatou que ele é fiel ao seu horário de trabalho, quando precisa ir ao médico sempre avisa e faz questão de compensar depois; em contrapartida, quando foi solicitado a fazer horas-extra não aceitou (pois fugia da sua rotina) e foi respeitado.

Ao ser indagado sobre se o fato desse colaborador ser autista afetava em algum rendimento ou função; o entrevistado categoricamente respondeu que não afetou em nenhum momento suas funções, inclusive foi trocado o sistema interno recentemente e avisando com grande antecedência e introduzindo aos poucos, e ele se adaptou sem maiores problemas.

Quando perguntado sobre sua opinião sobre a baixa oferta de contratação de mão-de-obra autista, respondeu que infelizmente poucos conhecem os atributos dos autistas, pois se assim fosse teriam maior aproveitamento de sua companhia e de seu trabalho.

$\mathrm{Na}$ entrevista com o colaborador diagnosticado com Transtorno Espectro Autista, foi ele inquerido sobre sua formação e qualificação profissional; respondeu que é formado em Jornalismo, mas nunca exerceu sua profissão, sempre trabalhou como freelancer, e nunca compreendia por que não o contratavam. Então, o diagnóstico de autismo foi para ele "um alívio".

Revelou que tinha trinta anos de idade quando recebeu o diagnóstico pelo psiquiatra, que lhe indicou uma empresa especializada na inserção de mão de obra autista no mercado de trabalho.

Outra questão direcionada foi como ocorreu o processo do diagnóstico até ser contratado. Expôs que procurou a agência indicada pelo psiquiatra, preencheu um formulário e ficou aguardando. Depois foi chamado para uma entrevista e foi convidado para entrar no próximo grupo que havia.

Ao iniciar seu treinamento passou por uma dinâmica com o Lego, visando montar e programar um robô. Após foi apresentado à metodologia SCRUM (abordagem empírica que aplica algumas ideias da teoria de controle de processos industriais para o desenvolvimento de softwares; o objetivo dessa metodologia é encontrar uma forma de trabalho dos membros da equipe para produzir o software de forma flexível e em um ambiente em constante mudança (Soares, 2004)). Com esse entendimento, foram desenvolvidos exercícios do aplicativo office (realizar plano teste, Excel, formulários e gráficos), fazendo concomitantemente adaptações da rotina de trabalho, finalizando o curso. 
Participou do recrutamento e seleção, pediram-lhe sigilo, passou por teste de avaliação de vídeo e inserir informações no Excel, fazer uso do Big Data para aferir o vídeo.

O colaborador ainda mencionou a importância que teve seu tutor (funcionário de suporte que o acompanhou na inclusão) para melhoria da sua adaptação em obter melhor qualidade em sua comunicação e serviço. A dificuldade inicialmente encontrada foi com a carga horária de oito horas diárias "preso" em um único ambiente, mas, aos poucos, foi se acostumando e hoje não há mais problemas. Relata que gosta do que faz, está aberto a mudanças de funções e cargos, mas quer continuar fazendo o que já faz, já recebeu proposta de outras empresas em que teria a possibilidade de crescer e não aceitou, por se identificar com o que faz atualmente e trabalhar perto de casa.

Ao ser entrevistado, demonstrou ansiedade, pois contou que fica nervoso ao falar de si mesmo ou falar com grande público ou em situações nas quais seja o centro das atenções, mas sem agravos ou consequências e tem procurado vencer essa barreira.

\section{Conclusão}

Conclui-se que os objetivos foram alcançados, identificando a capacidade produtiva de pessoas com TEA. Ainda, conclui-se que não basta ter leis, se não houver o poder fiscalizador e garantia sua eficiência. A proposta simbiose do perfil do autista associada ao tipo de tarefa que pode desenvolver permitiu compatibilizar o portador de TEA com as necessidades, habilidades e capacidades próprias das tarefas. Portanto, objetivando uma quebra de paradigmas pragmáticos, consequentemente ocasionando mudanças por parte dos empregadores e seus respectivos gestores. Acredita-se que possam contribuir para a reflexão sobre essa realidade de grande relevância social.

As pesquisas direcionam para conclusão de que as pessoas com TEA que foram comparadas com pessoas neurotípicas, possuíram igual ou maior capacidade produtiva para execução das suas tarefas. E indicam que os colaboradores autistas podem exercerem competentemente diversas funções, no entanto, quando essas se atrelam ao que gostam com às suas habilidades pessoais. A amostragem se restringiu a uma pequena quantidade por causa da natureza da abordagem e à preocupação das empresas em manter sigilo sobre seus procedimentos.

Encontrou-se dificuldade nas pequenas e médias empresas em terem interesse na mão de obra autista. Entretanto, a realidade explicitamente observada foi que, mesmo nas empresas de grande porte como as multinacionais ou até órgãos públicos, que em sua grande maioria, acabam contratando autistas por obrigação de lei e os alocam às funções insignificantes para seu potencial. Em contrapartida, o cenário estudado se centralizou nas empresas que já venceram o estigma do preconceito. Essas estão concentradas na Região Sudeste do Brasil, local com maior desenvolvimento em todos os aspectos, principalmente educacional, tecnológico e financeiro ficando a preocupação ainda maior para as demais regiões e / ou classes sociais mais desfavorecidas.

Para trabalhos futuros deixa-se a expansão da pesquisa que ainda se encontra no estágio embrionário e com grande escassez de pesquisas e discussões da empregabilidade de pessoas com TEA no Brasil. Portanto deixa-se para trabalhos futuros pesquisar uma maior amostragem, assim como, também outras ramificações sobre o tema.

\section{Agradecimentos}

Fica registrado o agradecimento ao PROSUP/CAPES pela confiança ao proporcionar bolsa - Código de Financiamento 001. Também as empresas, suas respectivas gestoras e colaboradores que foram a fonte de dados para essa pesquisa. 


\section{Referências}

Anjos, M. C. G. dos, Bezerra, S. B., Farias, A. de A., Marinho, G. de O., \& Barreto, J. de O. P. (2016). A Pessoa com Deficiência no Mercado de Trabalho e suas Implicações. ID on line Revista De Psicologia, 10(29), 51-70. https://doi.org/10.14295/idonline.v10i1.384

Attwood, A. (1998). Asperger's syndrome: A guide for parents and professionals. Jessica Kingsley Publishers.

Bernick, M., \& Holden, R. (2018a). The Autism Job Club:The Neurodiverse Workforce in the New Normal of Employment, (2 ed). Skyhorse Publishing. https://books.apple.com/mt/book/the-autism-job-club/id1448351528

Bernick, M., \& Holden, R. (2018b). The Autism Job Club: The Neurodiverse Workforce in the New Normal of Employment. Simon and Schuster.

Brasil, C. C. (2012). Lei N $N^{o}$ 12.764, De 27 De Dezembro De 2012-Dados da Norma-Portal Câmara dos Deputados. http://www2.camara.leg.br/legin/fed/lei/2012/lei-12764-27-dezembro-2012-774838-norma-pl.html

Cardoso, J., Sousa, N. M. F. R. de, \& Oliveira, F. P. (2021). Arte-Educação, Transtorno do Espectro Autista-TEA e possibilidades educativas. Research, Society and Development, 10(5), e18810514842-e18810514842. https://doi.org/10.33448/rsd-v10i5.14842

Deluiz, N. (2017). A globalização econômica e os desafios à formação profissional. Boletim Técnico do Senac, 30(3), 73-79.

Engels, F. (2018). O Papel Do Trabalho Na Transformação Do Macaco Em Homem (1876). Revista Trabalho Necessário, 4(4). http://periodicos.uff.br/trabalhonecessario/article/view/4603

Gracioli, M. M., \& Bianchi, R. C. (2014). Educação Do Autista No Ensino Regular: Um Desafio À Prática Pedagógica. Nucleus, 11(2), 125-138. https://doi.org/10.3738/1982.2278.989

Hendricks, D. R. (2010). Employment and adults with autism spectrum disorders: Challenges and strategies for success. Journal of Vocational Rehabilitation, 2, 125-134. https://doi.org/10.3233/JVR-2010-0502

Hillier, A., Campbell, H., Mastriani, K., Izzo, M. V., Kool-Tucker, A. K., Cherry, L., \& Beversdorf, D. Q. (2016). Two-Year Evaluation of a Vocational Support Program for Adults on the Autism Spectrum: Career Development for Exceptional Individuals. https://doi.org/10.1177/08857288070300010501

Instituto Ethos e da Rede Empresarial de Inclusão. (2019). Indicadores Ethos-REIS para Inclusão da Pessoa com Deficiência. Thalita Paratela. https://www.ethos.org.br/cedoc/indicadores-ethos-guia-tematico-para-inclusao-da-pessoa-com-deficiencia/\#.WuITaS7wY2x

Klin, A. (2006). Autismo e síndrome de Asperger: Uma visão geral. Brazilian Journal of Psychiatry, 28, s3-s11. https://doi.org/10.1590/S151644462006000500002

Lobato, B. C. (2009). Pessoas com deficiência no mercado de trabalho: Implicações da Lei de cotas. 6. https://repositorio.ufscar.br/handle/ufscar/3002 MOREIRA, D. A. (2017). Administração Da Produção E Operações. Editora Saraiva.

Orsmond, G. I., Shattuck, P. T., Cooper, B. P., Sterzing, P. R., \& Anderson, K. A. (2013). Social participation among young adults with an autism spectrum disorder. Journal of Autism and Developmental Disorders, 43(11), 2710-2719. https://doi.org/10.1007/s10803-013-1833-8

Parr, A. D., \& Hunter, S. T. (2014). Enhancing work outcomes of employees with autism spectrum disorder through leadership: Leadership for employees with autism spectrum disorder. Autism: The International Journal of Research and Practice, 18(5), 545-554. https://doi.org/10.1177/1362361313483020

Peinado, J., \& Graemi, A. R. (2007). Administração da produção (Operações industriais e de serviços). Centro Universitário Positivo - UnicenP. https://issuu.com/jurandir_peinado/docs/livro2folhas

Ribeiro, J. F. A. (2015). Perturbação do espectro do autismo: Artigo de revisão das comorbidades associadas [Universidade de Lisboa]. http://repositorio.ul.pt/handle/10451/25713

Ribeiro, M. A., \& Carneiro, R. (2009). A inclusão indesejada: As empresas brasileiras face à lei de cotas para pessoas com deficiência no mercado de trabalho. Organizações \&amp; Sociedade, 16(50), 545-564. https://doi.org/10.1590/S1984-92302009000300008

RICHARDSON, R. Jarry. (2015). Pesquisa Social: Métodos e Técnicas (3ºd). ATLAS.

Ritvo, E., Brothers, A. M., Freeman, B. J., \& Pingree, C. (1988). Eleven possibly autistic parents. Journal of Autism and Developmental Disorders, 18(1), 139-143. https://doi.org/10.1007/BF02211824

Robertson, S. M. (2009). Neurodiversity, Quality of Life, and Autistic Adults: Shifting Research and Professional Focuses onto Real-Life Challenges. Disability Studies Quarterly, 30(1), Article 1. https://doi.org/10.18061/dsq.v30i1.1069

Rosqvist, H. B., \& Keisu, B.-I. (2012). Adaptation or recognition of the autistic subject? Reimagining autistic work life: Deconstructing the notion of "real jobs" in the Swedish autistic self-advocacy movement. Journal of Vocational Rehabilitation, 37(3), 203-212. https://doi.org/10.3233/JVR-2012-0615

Roux, A. M., Shattuck, P. T., Cooper, B. P., Anderson, K. A., Wagner, M., \& Narendorf, S. C. (2013). Postsecondary Employment Experiences Among Young Adults With an Autism Spectrum Disorder RH: Employment in Young Adults With Autism. Journal of the American Academy of Child and Adolescent Psychiatry, 52(9), 931-939. https://doi.org/10.1016/j.jaac.2013.05.019

Scott, M., Jacob, A., Hendrie, D., Parsons, R., Girdler, S., Falkmer, T., \& Falkmer, M. (2017). Employers' perception of the costs and the benefits of hiring individuals with autism spectrum disorder in open employment in Australia. PLOS ONE, 12(5), e0177607. https://doi.org/10.1371/journal.pone.0177607

Scott, M., Milbourn, B., Falkmer, M., Black, M., Bölte, S., Halladay, A., Lerner, M., Taylor, J. L., \& Girdler, S. (2019). Factors impacting employment for people with autism spectrum disorder: A scoping review. Autism, 23(4), 869-901. https://doi.org/10.1177/1362361318787789 
Research, Society and Development, v. 10, n. 6, e26110615760, 2021

(CC BY 4.0) | ISSN 2525-3409 | DOI: http://dx.doi.org/10.33448/rsd-v10i6.15760

Seaman, R. L., \& Cannella-Malone, H. I. (2016). Vocational Skills Interventions for Adults with Autism Spectrum Disorder: A Review of the Literature. https://doi.org/10.1007/s10882-016-9479-z

Silva, A. C. M. da. (2013). Autismo: O acesso ao trabalho como efetivação dos direitos humanos. http://localhost:8080/tede/handle/tede/509

SILVA JÚNIOR, S. D. D., \& COSTA, F. J. D. (2014). Mensuração e Escalas de Verificação: Uma Análise Comparativa das Escalas de Likert e Phrase Completion. XVII SEMEAD Seminários em Administração. http://sistema.semead.com.br/17semead/resultado/trabalhosPDF/1012.pdf

Slack, N., Chambers, S., Johnston, R., \& tradução Henrique Luiz Corrêa. (2009). Administração da produção (3 ed.). Atlas S.A.

Soares, M. dos S. (2004). Metodologias Ágeis Extreme Programming e Scrum para o Desenvolvimento de Software. Revista Eletrônica de Sistemas de Informação, 3(1). https://doi.org/10.21529/RESI.2004.0301006

Staudt, F. H., Coelho, A. S., \& Gonçalves, M. B. (2011). Determinação da capacidade real necessária de um processo produtivo utilizando cadeia de Markov. Production, 21(4), 634-644. https://doi.org/10.1590/S0103-65132011005000058

Toldrá, R. C. (2009). Políticas afirmativas: Opinião das pessoas com deficiência acerca da legislação de reserva de vagas no mercado de trabalho. Revista de Terapia Ocupacional da Universidade de São Paulo, 20(2), 110-117. https://doi.org/10.11606/issn.2238-6149.v20i2p110-117

Van Wieren, T. A., Reid, C. A., \& McMahon, B. T. (2008). Workplace discrimination and autism spectrum disorders: The National EEOC Americans with Disabilities Act Research project. Work, 31(3), 299-308. 